Research article

\title{
Attitudes, beliefs, and perceived norms about corporal punishment and related training needs among members of the "American Professional Society on the Abuse of Children"
}

\author{
Catherine A. Taylor ${ }^{\mathrm{a}, *}$, Julia M. Fleckman ${ }^{\mathrm{a}}$, Shawna J. Lee

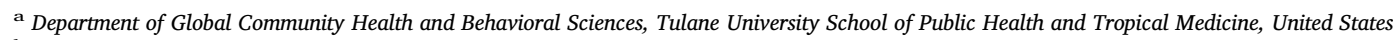 \\ ${ }^{\mathrm{b}}$ University of Michigan, School of Social Work, United States
}

\section{A R T I C L E I N F O}

\section{Keywords:}

Corporal punishment

Professionals

Attitudes

Social norms

Training

\begin{abstract}
A B S T R A C T
Hitting children for disciplinary purposes (i.e., spanking or corporal punishment [CP]) is a strong risk factor for child physical abuse and is highly prevalent in the U.S. Yet, little is currently known about the relevant attitudes, beliefs, or training needs of key professionals who often advise parents regarding child discipline strategies. A survey of the American Professional Society on the Abuse of Children (APSAC) membership, comprised of mental health professionals, physicians, child welfare professionals, and other professionals in the child maltreatment field, was conducted to assess attitudes, beliefs, perceived norms, training needs, and motivations to change norms regarding $\mathrm{CP}(N=571$, response rate $=51 \%)$. Most respondents agreed that spanking is a bad disciplinary technique $(82 \%)$, is harmful for children $(74 \%)$, and leads to negative outcomes $(M=3.0, S D=0.6)$ more frequently than positive outcomes $(M=2.1$, $\mathrm{SD}=0.6 ; t=20.8 ; p<0.0001)$ for children. Professionals reported perceiving that their colleagues' level of endorsement of $\mathrm{CP}(\mathrm{M}=2.4, \mathrm{SD}=1.0)$ was higher than their own $(\mathrm{M}=1.9$, $\mathrm{SD}=1.0 ; t(568)=-10.7, p<0.0001)$ though still below the midpoint. Professionals reported high levels of preparedness to effectively advise parents on non-physical child discipline strategies, but reported perceiving lower levels of preparedness amongst their colleagues. They reported highly valuing giving such advice to parents and being very motivated to participate in activities designed to change social norms regarding CP. Most APSAC members are poised to change these norms and, in doing so, to help reduce rates of child physical abuse in the U.S.
\end{abstract}

\section{Introduction}

Corporal punishment (CP) is a commonly used form of child discipline in the U.S. and around the globe. CP, referred to more commonly by terms such as spanking, hitting, popping, or whooping, is "the use of physical force with the intention of causing a child to experience pain, but not injury, for the purpose of correcting or controlling the child's behavior" (Donnelly \& Straus, 2005; p. 3). A majority of children in the U.S. experience CP (Mackenzie, Nicklas, Brooks-Gunn, \& Waldfogel, 2015; Taylor, Lee, Guterman, \& Rice, 2010; Zolotor, Robinson, Runyan, Barr, \& Murphy, 2011). This is problematic because CP is a strong risk factor for child physical abuse as well as other poor outcomes for children (Gershoff \& Grogan-Kaylor, 2016). As CP increases, so does the use of more severe acts of physical aggression and psychological aggression toward the child (Gagne, Tourigny, Joly, \& Pouliot-Lapointe, 2007; Taylor, Guterman, Lee, \& Rathouz, 2009). CP also raises risk for lifetime mental and physical health conditions (Afifi, Mota,

\footnotetext{
* Corresponding author.

E-mail address: ctaylor5@tulane.edu (C.A. Taylor).
} 
Macmillan, \& Sareen, 2013; Afifi, Mota, Dasiewicz, MacMillan, \& Sareen, 2012). No studies have found that CP leads to positive outcomes (e.g., Altschul, Lee, \& Gershoff, 2016). In sum, CP is a highly prevalent risk factor for child physical abuse as well as other poor outcomes for children's health and development.

Overall approval of CP among U.S. adults is very high, with most men (76\%) and women (65\%) believing that CP is a necessary form of child discipline (Child Trends Databank, 2015). These high rates of endorsement of CP are problematic in part because they are a strong predictor of its use (Ateah \& Durrant, 2005; Holden, Coleman, \& Schmidt, 1995; Vittrup, Holden, \& Buck, 2006). Endorsing the use of CP also predicts a decreased likelihood of perceiving and reporting child abuse (Ashton, 2001; Jent et al., 2011), even among physicians (Tirosh, Shechter, Cohen, \& Jaffe, 2003). With the population-level norms and risks of CP to children wellestablished, the goal of the current study was to fill a crucial gap in knowledge regarding our understanding of current norms and training needs of professionals related to parents' use of CP and advising parents about child discipline options.

\subsection{Why focus on attitudes and beliefs of professionals regarding $C P$}

In order to change population-level norms regarding $\mathrm{CP}$, it is essential to understand which modifiable factors shape their formation. Attitudes toward a behavior are at least partially influenced by expected outcomes and perceived norms regarding the behavior (Ajzen, 2005). People who expect more positive outcomes and fewer negative outcomes from CP are more supportive of its use (Gagne et al., 2007; Holden, Miller, \& Harris, 1999; Taylor, Hamvas, Rice, Newman, \& DeJong, 2011). Further, parents' approval of $\mathrm{CP}$ is strongest when they perceive that professionals whom they trust to advise them about parenting, such as pediatricians, are supportive of CP use (Taylor, Hamvas, Rice et al., 2011). Hence the attitudes and injunctive norms of these professionals may have substantial influence on changing parenting norms regarding CP. Medical professionals, particularly pediatricians, are the group that parents trust the most when seeking advice about parenting (Fortson, Moseley, \& Burton, 2013; Taylor, Moeller, Hamvas, \& Rice, 2013; Walsh, 2002). Mental health professionals, such as psychologists and social workers, are another important group that parents trust for such advice (Taylor et al., 2013; Walsh, 2002). Many professional organizations for these groups in the U.S. have clear policy statements discouraging the use of CP (e.g., American Academy of Child and Adolescent Psychiatry, 2012; American Academy of Pediatrics, 2014; Wolraich et al., 1998).

However, the current injunctive norms (i.e., shared beliefs among a group about how persons ought to act; Cialdini, Reno, \& Kallgren, 1990) among professionals on this topic are not clear. In a survey of Ohio physicians, $79 \%$ of family physicians and $59 \%$ of pediatricians supported the use of CP despite evidence that it can be detrimental and is neither effective nor necessary as a discipline strategy (McCormick, 1992; p.3161). An American Academy of Pediatrics (1998) survey reported that 31\% of pediatricians were completely opposed to CP, 53\% were generally opposed but reported it was sometimes effective, and $14 \%$ supported its use. Further, only $49 \%$ discouraged any use of CP and $42 \%$ conditionally recommended use of CP. A survey of psychologists found that $70 \%$ would not recommend parents use spanking and $30 \%$ would sometimes suggest spanking (Schenck, Lyman, \& Bodin, 2000, p. 27). Beliefs that CP leads to negative outcomes were linked with a lesser likelihood of recommending CP use.

More recently, Hornor et al. (2015) found in a survey of health care professionals, mostly nurses, that although many thought spanking was sometimes acceptable ( $82 \%)$ and necessary $(40 \%)$ as a disciplinary technique, most thought that it can be abusive (77\%) and nonphysical discipline is more effective (53\%). Responses varied widely depending on how frequently the respondent was spanked as a child: those who were frequently spanked were more likely than those who were not to report that spanking is sometimes necessary; and those who were never spanked were more likely than those who were frequently spanked to report that nonphysical forms of discipline are more effective.

\subsection{Why perceived norms and training needs of professionals regarding CP matter}

Perceived norms have long been known to influence behavior (Berkowitz, 2003; Bohner et al., 1998; Reno, Cialdini, \& Kallgren, 1993). For example, those that believe that their colleagues think a certain way might feel pressure to think or act in the same manner. One of the few studies to assess perceived professional norms on this topic found that although $58 \%$ of direct care medical center staff thought that spanking was not a good disciplinary technique, only $39 \%$ reported perceiving that their colleagues felt the same way (Gershoff et al., 2016). Another study found that about two-thirds of psychologists reported that their colleagues' recommendations to parents regarding $\mathrm{CP}$ were similar to their own; however, the other third were not sure if they were similar (30\%) or thought they were dissimilar (5\%; Schenck et al., 2000). Professionals who think their opinions are not in line with actual norms may behave differently than those who do.

For example, the way professionals advise parents about child discipline appears to vary widely. Many parents have identified a lack of guidance regarding discipline strategies as a crucial unmet need during primary care visits (Olson et al., 2004). In addition, at least a substantial minority of professionals are still recommending CP to parents (Knox \& Brouwer, 2008). Many professionals may not be getting appropriate training on advising parents about child discipline strategies. It might also be that perceived barriers (e.g., time, reimbursement, incentives, or cultural concerns) could prevent professionals from providing developmentally appropriate advice about discipline to parents (Sege, Hatmaker-Flanigan, De Vos, Levin-Goodman, \& Spivak, 2006).

\subsection{Study objectives}

We know that despite the abundance of empirical evidence against the use of CP, many parents still use it. We also know that the 
advice of key professionals—such as pediatricians and mental health professionals—matters in terms of parents' attitudes toward and use of CP. However, we lack an understanding of the current attitudes, beliefs, and perceived norms of such professionals regarding the use of CP. Most studies that have examined professionals' attitudes, beliefs, and/or norms related to $\mathrm{CP}$, as we have reviewed above, are more than 15 years old, with Gershoff et al. (2016) and Hornor et al. (2015) being notable exceptions. In fact, to our knowledge, no survey such as this has ever been conducted on a national organization of child maltreatment professionals. Filling this knowledge gap is crucial if we are to effectively bridge the divide between what we know about the impact of CP and what we can do to prevent it. If these professionals support the use of $\mathrm{CP}$, and they are not aware of the negative effects of CP on children, then increased professional training on this topic is needed. If these professionals are found to misperceive the norms amongst their colleagues, then this misperception should be corrected so that it does not unduly influence their behaviors and advice given on this topic. Furthermore, understanding these professional norms can help to move organization, state, and national level policies against CP forward. These all are essential points of knowledge for advancing efforts to prevent child physical abuse and the use of CP.

The objective of this study was to fill these crucial gaps in knowledge by assessing three main research questions among a national organization of professionals working in the field of child maltreatment: 1) what are the current actual and perceived injunctive norms (shared attitudes and expected outcomes) regarding the use of CP among this group; 2) what are the perceived training needs and motivations of this group relevant to changing CP norms; and 3) how do each of these constructs vary by key respondent characteristics, as this might influence targeted training recommendations? The survey assessed characteristics that attitudes toward $\mathrm{CP}$ are known to vary by in the general population such as gender, race, and experiencing CP during childhood (Child Trends Databank, 2015; Gagne et al., 2007; Taylor, Hamvas, Rice et al., 2011). We also considered factors such as type of profession and years of experience. Given the abundance of empirical findings over the past two decades that do not support the use of $\mathrm{CP}$, we anticipate that support for the use of $\mathrm{CP}$ amongst professionals will be relatively low. Yet, we also anticipate that there may still be gaps in training needs to be addressed. We hope the results of this study will be used to advance professional counseling practices with parents, trainings for professionals, and new policies at all levels relevant to ending the use of CP in our society.

\section{Method}

\subsection{Participants}

The study population was comprised of the full membership list of the American Professional Society on the Abuse of Children (APSAC). APSAC is one of the leading U.S.-based ( $<1 \%$ of membership is non-U.S.-based) professional organizations of individuals working in the field of child welfare and well-being. APSAC provides educational and training seminars, publications, and professional conferences related to child maltreatment and child welfare. Most participants $(N=571)$ identified themselves as mental health professionals/counselors (25.7\%), physicians (21.4\%), or child welfare professionals (12.8\%). Other professional groups (less than $10 \%$ each) included nurses, academic researchers, forensic interviewers, law enforcement/criminal justice professionals, child advocacy staff, government/policy professionals, and attorneys. Most were female (81.6\%), worked full time (78.3\%), and had 15 years or more of professional experience (68.5\%). Also, most were White (87.4\%) with very few racial minority groups (e.g., 3.2\% Black, 1.8\% Asian). Most experienced being spanked or hit with a hand or an object by a parent growing up either rarely (37.0\%) or sometimes (33.6\%); whereas, fewer reported never being hit (15.6\%) or being hit often (12.8\%). (To assess this, we asked: "While you were growing up, during your first 18 years of life, did any of your parents, including step-parents or other caregivers, ever spank or hit you with a hand or an object?")

\subsection{Procedure}

All 1128 members of APSAC between June 2, 2015 and July 21, 2015 were invited by email to participate in this survey, which took ten minutes or less to complete. Upon completion of the survey, participants were given the opportunity to enter into a raffle for a \$200 Amazon gift card. No personally identifying information was collected except for those individuals who voluntarily entered the raffle following survey completion; however, these data were gathered and stored apart from the survey responses to maintain anonymity. APSAC staff sent email reminders to complete the survey on a weekly basis through July 21,2015 . The final response rate was $51 \%(\mathrm{~N}=571)$. This study was considered exempt by the Institutional Review Board of the Tulane Human Research Protection Program.

\subsection{Measures}

Table 1 presents a correlation matrix of all eight measured constructs. Validity of all measures was supported given that all constructs were significantly correlated with attitudes toward CP in ways that were expected. Expected positive outcomes of CP and perceived positive attitudes of colleagues toward CP were both strongly positively correlated with respondents' reporting positive attitudes toward CP. All remaining constructs (expected negative outcomes of using CP, preparedness to advise parents about child discipline, perceived professional norms of preparedness about advising parents about child discipline, perceived value of advising parents about child discipline, and motivation to participate in activities to change norms regarding the use of $\mathrm{CP}$ ) were all negatively correlated with respondents' reporting having positive attitudes toward CP. Cronbach's alpha reliability scores for all eight constructs are reported in Table 2. 
Table 1

Correlation Matrix of Measures Assessing Attitudes, Perceived Norms, and Beliefs Regarding Corporal Punishment (CP) and Advising Parents about Child Discipline $(\mathrm{N}=571)$.

\begin{tabular}{|c|c|c|c|c|c|c|c|c|}
\hline Measure & 1 & 2 & 3 & 4 & 5 & 6 & 7 & 8 \\
\hline 1. Positive attitudes toward $\mathrm{CP}$ & 1.00 & & & & & & & \\
\hline 2. Perceived positive attitudes of colleagues toward CP & $0.36 * * *$ & 1.00 & & & & & & \\
\hline 3. Expected negative outcomes of using CP & $-0.59 * * *$ & $-0.19 * * *$ & 1.00 & & & & & \\
\hline 4. Expected positive outcomes of using $\mathrm{CP}$ & $0.62 * * *$ & $0.25 * * *$ & $-0.54 * * *$ & 1.00 & & & & \\
\hline 5. Preparedness to advise parents about child discipline & $-0.27 * * *$ & $-0.18 * *$ & $0.18 * * *$ & $-0.30 * * *$ & 1.00 & & & \\
\hline $\begin{array}{l}\text { 6. Perceived professional norms of preparedness about advising } \\
\text { parents about child discipline }\end{array}$ & $-0.13 * *$ & $-0.29 * * *$ & 0.03 & -0.09 & $0.47 * * *$ & 1.00 & & \\
\hline 7. Perceived value of advising parents about child discipline & $-0.22 * * *$ & $-0.17 * * *$ & $0.14 * *$ & $-0.21 * * *$ & $0.67 * * *$ & $0.37 * * *$ & 1.00 & \\
\hline $\begin{array}{l}\text { 8. Motivation to participate in activities to change norms } \\
\text { regarding the use of } \mathrm{CP}\end{array}$ & $-0.37 * * *$ & -0.04 & $0.39 * * *$ & $-0.30 * * *$ & $0.51 * * *$ & $0.13 * *$ & $0.44 * * *$ & 1.00 \\
\hline
\end{tabular}

\subsubsection{Attitudes toward $C P$}

These were measured with four items from the Attitudes Toward Spanking (ATS) questionnaire (Holden, 2001). Participants were given the following instructions: "The following statements refer to YOUR OPINIONS toward spanking children. For the purposes of this survey, spanking refers to hitting a child with a hand or an object with the intention of causing pain, but not injury, for the purpose of correction or control of the child's behavior." The following four items were used on the survey: Spanking is a normal part of parenting; Sometimes the only way to get a child to behave is with a spank; When all is said and done, spanking is harmful for children; and Overall, spanking is a bad disciplinary technique. Responses were rated on a 5-point Likert scale ranging from $1=$ strongly agree to $5=$ strongly disagree. The first two items were reverse scored and an average score for the four items was calculated. Higher scores indicated more positive attitudes toward CP. These four ATS items were chosen based on their high item to scale reliability scores and recommendation of the author (G. Holden, personal communication, October 8, 2008), in order to maintain survey brevity, and because of their high reliability score from a prior study ( $\alpha=0.79$; Taylor, Hamvas, Rice et al., 2011). Alpha scores for the original ten item scale were high ( $\alpha=0.89$ to 0.91$)$ and validity, assessed through rates of using CP in the past week, was strong ( $r=0.73$; Holden, 2001).

\subsubsection{Perceived attitudes of colleagues toward $C P$}

Respondents were asked to tell us their "perception of the opinions of MOST OF YOUR COLLEAGUES WITHIN YOUR PROFESSION toward spanking children." The same four ATS items were used with 5-point Likert scale ranging from $1=$ strongly agree to 5 = strongly disagree for rating responses. Again, the first two items were reverse scored and an average score for the four items was calculated. Higher scores indicated more perceived positive attitudes of colleagues toward CP. We used Ajzen (2006) as a guide for constructing these perceived norms question; same as in (Gershoff et al., 2016; p. 58).

\subsubsection{Expected outcomes of using $C P$}

Respondents were asked: "How often do you think that spanking or hitting a child with a hand or an object for disciplinary

Table 2

Descriptive Statistics of Measures Assessing Attitudes, Perceived Norms, and Beliefs Regarding Corporal Punishment (CP) and Advising Parents about Child Discipline $(\mathrm{N}=571)$.

\begin{tabular}{|c|c|c|c|c|c|}
\hline Measures & $\mathrm{n}$ & $\alpha$ & Mean & SD & Actual Range \\
\hline 1. Attitudes toward $\mathrm{CP}^{\mathrm{a}, \mathrm{b}}$ & 569 & 0.81 & 1.86 & 0.96 & $1-5$ \\
\hline 2. Perceived attitudes of colleagues toward $\mathrm{CP}^{\mathrm{a}, \mathrm{b}}$ & 569 & 0.86 & 2.37 & 1.03 & $1-5$ \\
\hline 3. Expected negative outcomes of using $\mathrm{CP}^{\mathrm{c}, \mathrm{d}}$ & 568 & 0.89 & 3.01 & 0.56 & $1-5$ \\
\hline 4. Expected positive outcomes of using $\mathrm{CP}^{\mathrm{a}, \mathrm{d}}$ & 569 & 0.88 & 2.12 & 0.61 & $1-4.1$ \\
\hline 5. Preparedness to advise parents about child discipline $e^{e, f}$ & 458 & 0.86 & 3.88 & 0.88 & $1-5$ \\
\hline 6. Perceived professional norms of preparedness about advising parents about child discipline $\mathrm{e}^{\mathrm{e}, \mathrm{f}}$ & 453 & 0.71 & 2.92 & 0.87 & $1-5$ \\
\hline 7. Perceived value of advising parents about child discipline $e^{\mathrm{e}, \mathrm{f}}$ & 458 & 0.73 & 3.15 & 0.73 & $1-5$ \\
\hline 8. Motivation to participate in activities designed to change norms regarding the use of $\mathrm{CP}^{\mathrm{e}}$ & 564 & 0.71 & 3.75 & 0.93 & $1-5$ \\
\hline
\end{tabular}

Note: The potential range for all measures was $1-5$. Paired $t$-tests were conducted for measures 1 vs. $2(t(568)=-10.7, p<0.0001)$ and measures 3 vs. $4(t(567)$ $=20.8 ; p<0.0001$ ).

${ }^{\mathrm{a}}$ Lower scores indicate less endorsement or support for use CP.

b Reponses ranged from: $1=$ strongly agree, $2=$ somewhat agree, $3=$ neutral, $4=$ somewhat disagree, and $5=$ strongly disagree.

${ }^{c}$ Higher scores indicate less endorsement or support for use of CP.

${ }^{\mathrm{d}}$ Reponses ranged from: $1=$ never, $2=$ seldom, $3=$ sometimes, $4=$ most of the time, and $5=$ always.

e Reponses ranged from: $1=$ not at all, $2=$ a little, $3=$ moderately, $4=$ very, and $5=$ extremely.

f These measures were asked only for respondents who indicated that they worked directly with parents $(n=461)$. 
purposes leads to the child..." This question was followed by fourteen items used to assess this construct: seven positive outcomes and seven negative outcomes. This measure was based off of the Outcomes of Physical Punishment Scale (Durrant, RoseKrasnor, \& Broberg, 2003). Four items (marked by an asterisk*) came from that scale. The additional ten items were added based on more recent studies linking CP with poor outcomes (e.g., Afifi et al., 2013, 2012; Gershoff \& Grogan-Kaylor, 2016) and also to expand on the reasons parents provide for their use of CP (e.g., Taylor, Hamvas, \& Paris, 2011). Two subscales were assessed. The "positive outcomes" subscale included the following seven items: (1) being better behaved in the short-term, (2) being better behaved in the long-term, (3) being more respectful of parents*, (4) learning correct behavior, (5) having a better relationship with the parent, (6) having a decreased chance of being delinquent or incarcerated later in life, and (7) having a better sense of self control. The "negative outcomes" subscale included the following seven items: (8) being physically injured*, (9) being more aggressive*, (10) being physically abused, (11) experiencing long-term emotional upset*, (12) having poorer cognitive abilities, (13) having poorer mental health, and (14) having poorer physical health. Participants rated each item on a 5-point Likert scale ranging from $1=$ never to 5 always. For each subscale, an average score was calculated for each set of items.

\subsubsection{Beliefs about advising parents about child discipline}

Participants were asked to rate the following questions with regard to advising parents about using discipline that does not involve spanking or hitting a child with a hand or an object. Professional preparedness beliefs included: (1) How strongly do you believe that this is part of your job? (2) How well-trained do you feel you were to provide such advice? (3) How confident do you feel about your ability to provide such advice? and (4) How supported do you feel in your workplace to provide such advice? Perceived value beliefs included: (1) Do you give a high priority to providing such advice? (2) How highly do you think parents value such advice when you provide it? and (3) How likely do you think parents are to follow such advice when you provide it? Answers were scored on a 5-point Likert scale ranging from $1=$ not at all to $5=$ extremely. Scores were averaged so that final scores ranged from 1 to 5 . We developed these original items as we could not find an existing relevant measure.

\subsubsection{Perceived professional norms of preparedness about advising parents about child discipline}

Respondents were asked: (1) How well-trained do you think most people in your profession are to provide advice about using discipline that does not involve spanking or hitting a child with a hand or an object? (2) How confident do you think most people in your profession are to provide advice about using discipline that does not involve spanking or hitting a child with a hand or an object? (3) Was learning how to prevent child physical abuse before it occurs emphasized in your professional training or education? and (4) Was learning how to respond to child physical abuse cases after they occur emphasized in your professional training or education? Answers were scored on a 5-point Likert scale ranging from $1=$ not at all to $5=$ extremely. Scores were averaged so that final scores ranged from 1 to 5 . We developed these original items as we could not find an existing relevant measure.

\subsubsection{Motivation to change norms regarding CP of children}

Respondents were asked their level of motivation to participate in the following seven items: (1) Learn more about research findings on the effects of spanking on children, (2) Talk to parents about using discipline techniques that do not involve spanking, (3) Challenge parents' viewpoints that support the use of spanking, (4) Challenge colleagues' viewpoints that support the use of spanking, (5) Work with your employer to change policies related to the use of spanking (e.g., no hit zones), (6) Discuss with your colleagues discipline techniques that do not involve spanking, and (7) Learn about ways you can best intervene with parents when they spank children in your presence. Answers were scored on a 5-point Likert scale ranging from $1=$ not at all to $5=$ extremely. Scores were averaged so that final scores ranged from 1 to 5 . We developed these original items as we could not find an existing relevant measure.

\subsubsection{Perceived professional barriers to advising parents about child discipline}

Respondents were asked: "Which of the following items are barriers to you educating parents about using discipline that does not involve spanking? (If you do not interact with parents directly or do so very infrequently, which do you suspect are barriers to most APSAC professionals?)" Respondents were asked to indicate yes or no for all items: (1) lack of time, (2) lack of resources, (3) lack of incentive, (4) lack of reimbursement for time spent advising parents on this topic, (5) discomfort with the topic, (6) concern about cultural sensitivity, (7) lack of knowledge about how to best advise parents, (8) lack of training about how to best advise parents, (9) lack of knowledge about what types of strategies would be more effective than spanking, (10) belief that this is not an issue in your profession, and (11) are there other barriers? They were also asked: "What do you think will help remove or reduce any of the barriers just listed?" We developed this question and list of responses in consultation with other professionals as we could not find an existing relevant measure.

\subsection{Data analysis}

Our main research questions were: 1) what are the current actual and perceived injunctive norms (attitudes and expected outcomes) regarding the use of CP among this group; 2) what are the perceived training needs and motivations of this group relevant to changing CP norms; and 3) how do each of these constructs vary by key respondent characteristics and history of being spanked. To address questions 1 and 2, we conducted summary and descriptive statistics presented in Tables 2, 4, and 6. To further explore question 1, paired $t$-tests were conducted and results presented in Table 2 to compare two sets of variables: attitudes vs. perceived attitudes of colleagues; and expected negative vs. positive outcomes of CP. Question 3 was assessed using multivariable regression analyses with results presented in Tables 3 and 5 . 
Table 3

Attitudes, Perceived Norms, and Positive and Negative Beliefs about Corporal Punishment (CP) Regressed on Demographic Characteristics and History of Being Spanked as a Child $(n=548)$.

\begin{tabular}{|c|c|c|c|c|c|c|c|c|c|c|c|c|}
\hline & \multicolumn{3}{|c|}{ Positive attitudes } & \multicolumn{3}{|c|}{$\begin{array}{l}\text { Perceived positive attitudes toward CP } \\
\text { among colleagues }\end{array}$} & \multicolumn{3}{|c|}{$\begin{array}{l}\text { Positive expected outcomes of } \\
\text { using CP }\end{array}$} & \multicolumn{3}{|c|}{ Negative expected outcomes } \\
\hline & $B$ & $S E B$ & $\beta$ & $B$ & $S E B$ & $\beta$ & $B$ & $S E B$ & $\beta$ & $B$ & $S E B$ & $\beta$ \\
\hline \multicolumn{13}{|c|}{ Gender (ref = Female) } \\
\hline Male & 0.25 & 0.11 & $0.10^{*}$ & 0.26 & 0.12 & $0.10^{*}$ & 0.21 & 0.07 & $0.13^{* *}$ & -0.13 & 0.06 & $-0.09 *$ \\
\hline \multicolumn{13}{|c|}{ Race (ref $=$ White) } \\
\hline Non-White & -0.04 & 0.13 & -0.01 & -0.06 & 0.15 & -0.02 & 0.12 & 0.08 & 0.06 & 0.17 & 0.08 & $0.10^{*}$ \\
\hline \multicolumn{13}{|c|}{ Profession (ref $=$ Other) } \\
\hline Child Welfare & -0.13 & 0.13 & -0.04 & 0.18 & 0.15 & 0.01 & -0.04 & 0.08 & -0.02 & 0.11 & 0.08 & 0.06 \\
\hline Mental Health & -0.12 & 0.10 & -0.05 & -0.33 & 0.11 & $-0.14 * *$ & -0.14 & 0.06 & $-0.10^{*}$ & 0.10 & 0.06 & 0.08 \\
\hline Physician & -0.12 & 0.11 & -0.05 & -0.02 & 0.12 & -0.01 & -0.17 & 0.07 & $-0.12^{*}$ & 0.00 & 0.06 & 0.00 \\
\hline \multicolumn{13}{|c|}{ Years of Experience (ref $=<14$ yrs) } \\
\hline $15-24$ yrs & 0.06 & 0.11 & 0.03 & 0.09 & 0.12 & 0.04 & 0.00 & 0.07 & 0.00 & -0.12 & 0.06 & -0.09 \\
\hline $25-34$ yrs & -0.10 & 0.11 & -0.05 & -0.01 & 0.12 & -0.01 & -0.14 & 0.07 & $-0.10^{*}$ & -0.03 & 0.06 & -0.02 \\
\hline $35+y r s$ & -0.26 & 0.12 & $-0.11^{*}$ & -0.11 & 0.13 & -0.04 & -0.18 & 0.07 & $-0.11 *$ & 0.06 & 0.07 & 0.04 \\
\hline \multicolumn{13}{|c|}{ Spanked as Child (ref = Rarely) } \\
\hline Never & -0.42 & 0.12 & $-0.16^{* *}$ & -0.12 & 0.13 & -0.04 & -0.18 & 0.07 & -0.11 & 0.24 & 0.07 & $0.16^{* * *}$ \\
\hline Sometimes & 0.14 & 0.10 & 0.07 & 0.07 & 0.11 & 0.03 & 0.25 & 0.06 & $0.20 * * *$ & -0.03 & 0.06 & -0.03 \\
\hline Often & -0.01 & 0.13 & -0.00 & 0.05 & 0.14 & 0.02 & 0.14 & 0.08 & 0.08 & 0.10 & 0.08 & 0.06 \\
\hline
\end{tabular}

Note: Sample $\mathrm{n}$ is less than $(\mathrm{N}=571)$ due to missing values.

*p $<0.05 ; * \mathrm{p}<0.01 ; * * \mathrm{p}<0.001$.

\section{Results}

\subsection{Actual and perceived injunctive norms of professionals regarding $C P$}

Overall, APSAC professionals had negative attitudes toward spanking. Most reported that they did not think that spanking was the only way to get a child to behave (84\%) or that it was a normal part of parenting (74\%); and most agreed that spanking is a bad disciplinary technique overall (82\%) or is harmful for children (74\%). Participants' perceptions of their colleagues' attitudes followed a similar pattern. However, they felt their colleagues were more likely to endorse spanking than were they. Most respondents perceived that their colleagues did not think that spanking was the only way to get a child to behave (64\%) nor that spanking is a normal part of parenting (59\%); most also thought their colleagues would agree that spanking is a bad disciplinary technique overall $(69 \%)$ and that it is harmful for children (62\%). Hence there was an 11-20\% gap between participants' attitudes toward CP and their

Table 4

Beliefs about Advising Parents Regarding Child Discipline that Does Not Involve Corporal Punishment (CP) (n = 461).

\begin{tabular}{|c|c|c|c|c|}
\hline & A little/Not at all\% & $\begin{array}{l}\text { Moderately } \\
\%\end{array}$ & $\begin{array}{l}\text { Very } \\
\%\end{array}$ & $\begin{array}{l}\text { Extremely } \\
\%\end{array}$ \\
\hline \multicolumn{5}{|l|}{ Professional Preparedness to Advise } \\
\hline Feel confident in ability & 6.5 & 18.1 & 44.8 & 30.6 \\
\hline Feel supported in the workplace & 10.2 & 17.7 & 39.7 & 32.5 \\
\hline Feel well-trained & 14.0 & 22.4 & 36.8 & 25.0 \\
\hline Believe it is a part of their job & 12.3 & 16.8 & 31.2 & 39.7 \\
\hline \multicolumn{5}{|l|}{ Professional Preparedness Norms } \\
\hline Feel other professionals confident in ability & 31.3 & 41.6 & 23.8 & 3.2 \\
\hline Feel other professionals well-trained & 30.0 & 45.0 & 21.7 & 3.2 \\
\hline $\begin{array}{l}\text { Training emphasis on learning how to } \\
\text { prevent child physical abuse before it } \\
\text { occurs }\end{array}$ & 55.0 & 18.0 & 17.3 & 9.6 \\
\hline $\begin{array}{l}\text { Training emphasis on learning how to } \\
\text { respond to child physical abuse after it } \\
\text { occurs }\end{array}$ & 31.7 & 21.2 & 24.0 & 23.1 \\
\hline \multicolumn{5}{|l|}{ Value in Advising } \\
\hline Priority to giving advice & 11.7 & 24.9 & 38.6 & 24.7 \\
\hline Believe parents value advice & 23.3 & 49.9 & 23.1 & 3.7 \\
\hline Believe parents follow advice & 35.9 & 53.6 & 9.2 & 1.3 \\
\hline
\end{tabular}

Note: These measures were asked only for those respondents who indicated that they worked directly with parents. 
Table 5

Beliefs and Perceived Professional Norms of Preparedness about Advising Parents about Child Discipline, and Motivations to Change Norms Regarding Corporal Punishment (CP) Regressed on Demographic Characteristics and History of Being Spanked as a Child.

\begin{tabular}{|c|c|c|c|c|c|c|c|c|c|c|c|c|}
\hline & \multicolumn{3}{|c|}{$\begin{array}{l}\text { Professional preparedness to } \\
\text { advise parents }^{\mathrm{a}}\end{array}$} & \multicolumn{3}{|c|}{$\begin{array}{l}\text { Perceived professional preparedness } \\
\text { to advise parents }{ }^{\mathrm{a}}\end{array}$} & \multicolumn{3}{|c|}{$\begin{array}{l}\text { Perceived value of advising } \\
\text { parents }^{\mathrm{a}}\end{array}$} & \multicolumn{3}{|c|}{$\begin{array}{l}\text { Motivation to change norms } \\
\text { regarding } \mathrm{CP}^{\mathrm{b}}\end{array}$} \\
\hline & $B$ & $S E B$ & $\beta$ & $B$ & $S E B$ & $B$ & $B$ & $S E B$ & $\beta$ & $B$ & $S E B$ & $B$ \\
\hline \multicolumn{13}{|c|}{ Gender (ref = Female) } \\
\hline Male & -0.24 & 0.11 & $-0.10^{*}$ & -0.24 & 0.11 & $-0.11^{*}$ & 0.06 & 0.09 & 0.03 & -0.37 & 0.10 & $-0.15^{* * *}$ \\
\hline \multicolumn{13}{|c|}{ Race (ref = White) } \\
\hline Non-White & 0.27 & 0.13 & $0.09 *$ & 0.34 & 0.13 & $0.12^{*}$ & 0.26 & 0.11 & $0.11 *$ & 0.16 & 0.13 & 0.05 \\
\hline \multicolumn{13}{|c|}{ Profession (ref $=$ Other) } \\
\hline Child Welfare & 0.31 & 0.15 & $0.10 *$ & 0.31 & 0.15 & $0.10^{*}$ & 0.01 & 0.12 & 0.01 & 0.18 & 0.13 & 0.06 \\
\hline Mental Health & 0.61 & 0.10 & $0.32^{* * *}$ & 0.38 & 0.10 & $0.20 * * *$ & 0.42 & 0.08 & $0.27 * * *$ & 0.43 & 0.10 & $0.20 * * *$ \\
\hline Physician & 0.26 & 0.10 & $0.13^{*}$ & 0.10 & 0.11 & 0.05 & 0.06 & 0.08 & 0.04 & 0.15 & 0.10 & 0.07 \\
\hline \multicolumn{13}{|c|}{ Years of Experience (ref $=<15$ yrs) } \\
\hline $15-24$ yrs & 0.29 & 0.11 & $0.14 * *$ & 0.09 & 0.11 & 0.05 & 0.19 & 0.09 & $0.12 *$ & -0.04 & 0.11 & -0.02 \\
\hline $25-34$ yrs & 0.57 & 0.10 & $0.29 * * *$ & 0.11 & 0.11 & 0.06 & 0.49 & 0.08 & $0.31^{* * *}$ & 0.28 & 0.10 & $0.13^{* *}$ \\
\hline $35+y r s$ & 0.58 & 0.12 & $0.24 * * *$ & 0.15 & 0.13 & 0.06 & 0.40 & 0.10 & $0.20 * * *$ & 0.11 & 0.12 & 0.04 \\
\hline \multicolumn{13}{|c|}{ Spanked as Child (ref = Rarely) } \\
\hline Never & -0.03 & 0.12 & -0.01 & 0.03 & 0.13 & 0.01 & 0.12 & 0.10 & 0.06 & -0.07 & 0.12 & -0.03 \\
\hline Sometimes & -0.02 & 0.09 & -0.01 & -0.11 & 0.10 & -0.06 & 0.03 & 0.08 & 0.02 & -0.11 & 0.09 & -0.06 \\
\hline Often & 0.09 & 0.12 & 0.04 & 0.11 & 0.13 & 0.05 & 0.09 & 0.10 & 0.04 & 0.25 & 0.13 & $0.09 *$ \\
\hline
\end{tabular}

Note: ${ }^{\mathrm{a}}$ These measures were asked only for those respondents who indicated that they worked directly with parents ( $\mathrm{n}=461$ ); sample $\mathrm{n}$ for these analyses varied from 436 to 440 due to missing values. ${ }^{\text {b }}$ Sample $n=544$ due to missing values.

*p $<0.05 ; * * \mathrm{p}<0.01 ; * * \mathrm{p}<0.001$.

perceived attitudes amongst colleagues.

Descriptive statistics for quantitative measures, all assessed on a five point scale, are shown in Table 2. Respondents perceived significantly higher levels of endorsement for CP amongst their colleagues (measure 2) compared to their own level of endorsement for CP (measure 1) although both means were below the midpoint.

These attitudes and perceived norms varied by some assessed respondent characteristics. Men had and perceived amongst colleagues more positive attitudes toward CP than women. Those with 35 or more years of professional experience (versus less experience) and those who never experienced CP in childhood (versus those who had) had less positive attitudes toward CP. Mental health professionals perceived less positive attitudes toward CP amongst their colleagues than other professional groups (see Table 3 ).

\subsection{Expected outcomes of using $C P$}

As shown in Table 2, respondents expected negative outcomes from using CP (measure 3) significantly more frequently than positive outcomes (measure 4). These differences are shown on an item by item basis in Figs. 1 and 2. Most respondents reported that

Table 6

Level of Motivation to Change Norms Regarding Use of Spanking ( $\mathrm{N}=571)$.

\begin{tabular}{|c|c|c|c|c|}
\hline & $\begin{array}{l}\text { A little/Not } \\
\text { at all\% }\end{array}$ & $\begin{array}{l}\text { Moderately } \\
\%\end{array}$ & $\begin{array}{l}\text { Very } \\
\%\end{array}$ & $\begin{array}{l}\text { Extremely } \\
\%\end{array}$ \\
\hline \multicolumn{5}{|l|}{ How motivated are you to...? } \\
\hline $\begin{array}{l}\text { Learn more about research findings on the } \\
\text { effects of spanking on children }\end{array}$ & 9.2 & 21.1 & 43.4 & 26.2 \\
\hline $\begin{array}{l}\text { Challenge parents' viewpoints that support the } \\
\text { use of spanking }\end{array}$ & 13.3 & 20.0 & 41.1 & 25.5 \\
\hline $\begin{array}{l}\text { Talk to parents about using discipline } \\
\text { techniques that do not involve spanking }\end{array}$ & 11.4 & 17.3 & 39.8 & 31.6 \\
\hline $\begin{array}{l}\text { Learn about ways you can best intervene with } \\
\text { parents when they spank children in your } \\
\text { presence }\end{array}$ & 9.7 & 17.0 & 38.3 & 35.1 \\
\hline $\begin{array}{l}\text { Challenge colleagues' viewpoints that support } \\
\text { the use of spanking }\end{array}$ & 14.1 & 19.3 & 37.5 & 29.1 \\
\hline $\begin{array}{l}\text { Discuss with your colleagues discipline } \\
\text { techniques that do not involve spanking }\end{array}$ & 15.9 & 19.3 & 37.3 & 27.5 \\
\hline $\begin{array}{l}\text { Work with your employer to change policies } \\
\text { related to the use of spanking (e.g., no hit } \\
\text { zones) }\end{array}$ & 26.8 & 20.0 & 29.9 & 23.4 \\
\hline
\end{tabular}




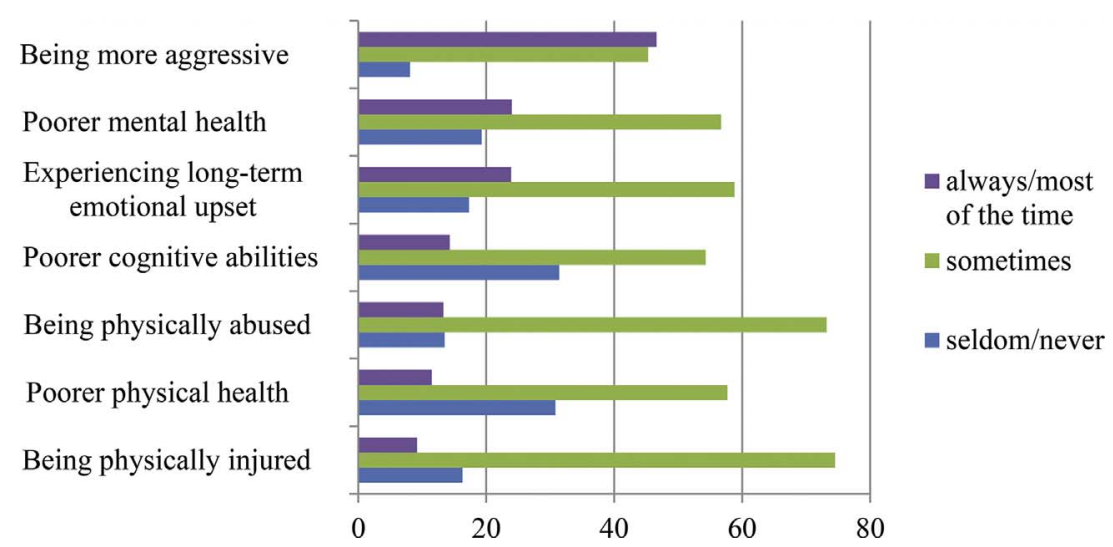

Fig. 1. Perceived negative outcomes of corporal punishment.Note: Findings for "always" and "most of the time" were merged; less than $4 \%$ of the sample chose "always" for each item. Findings for "seldom" and "never" were merged; less than $5 \%$ of the sample chose "never" for each item.

spanking sometimes, most of the time, or always results in a child being more aggressive (91.9\%), being physically abused (86.4\%), being physical injured (83.7\%), experiencing long-term emotional upset (82.7\%), having poorer mental health (80.7\%), having poorer physical health (69.2\%), and having poorer cognitive abilities (68.6\%). In contrast, most thought that spanking never or seldom results in a better relationship with the parent (82.8\%), a better sense of self-control (82.6\%), being better behaved in the long-run $(82.2 \%)$, a decreased chance of being delinquent or incarcerated later (74.5\%), being more respectful of parents $(71.5 \%)$, and learning correct behavior (60.7\%). However, most agreed that spanking sometimes results in the child being better behaved in the short-term (57.5\%).

Expected outcomes of CP differed by some respondent characteristics (see Table 3). Men expected more positive and fewer negative outcomes from using CP than women. Racial minority group members perceived more negative outcomes of using CP than Whites. Mental health professionals and physicians (versus those in other professions) as well as those with 25 or more years of professional experience (versus those with less) expected fewer positive outcomes from CP. Those who sometimes (versus never, rarely, or often) experienced $\mathrm{CP}$ in childhood reported expecting significantly more positive outcomes from CP. Those who never experienced $\mathrm{CP}$, versus those who had, perceived significantly more negative outcomes from CP.

\subsection{Advising parents about child discipline: preparedness, perceived norms, and value}

Most participants (80.7\%) interacted directly with parents as part of their jobs. Of those $(n=461)$, most felt well prepared in advising parents about using child discipline strategies other than hitting or spanking: most felt very or extremely confident in their ability to provide such advice (76\%), supported in their workplace to do so (73\%), well-trained to do so (62\%), and reported that it was a part of their job (71\%). In contrast, respondents' perceptions of profession-wide preparedness in providing parents with such advice were considerably lower. A minority felt that most people in their profession were very or extremely well-trained (25\%) or confident in (27\%) in providing such advice. Also, most (55\%) reported that learning how to prevent child physical abuse before it occurs was emphasized only a little or not at all in their professional training. Whereas only $32 \%$ reported that learning how to respond to child physical abuse after it occurs was emphasized only a little or not at all in their professional training.

Respondents' perceptions were mixed regarding the value of providing parents with advice about using non-physical discipline.

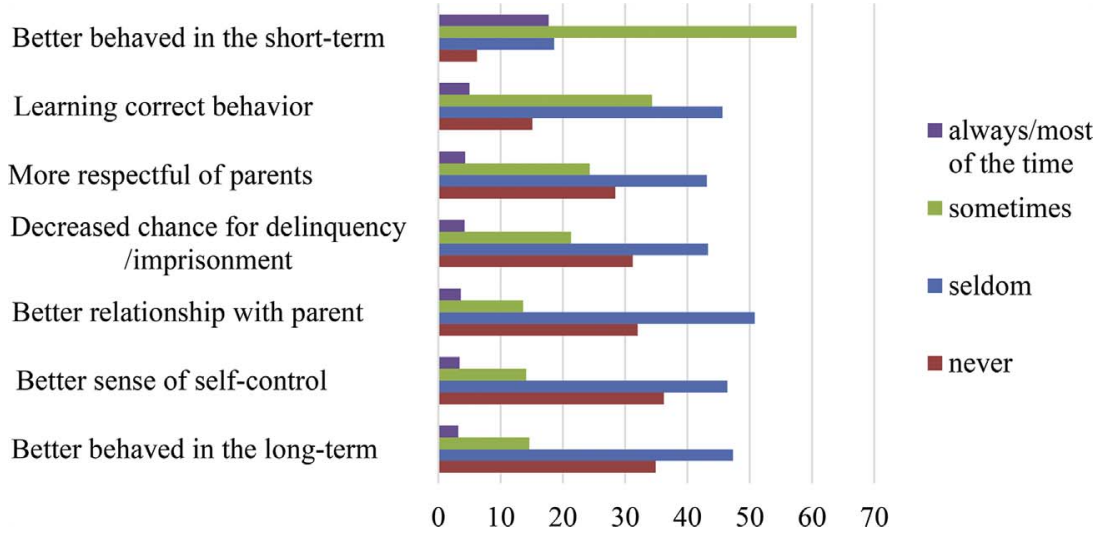

Fig. 2. Perceived positive outcomes of corporal punishment.Note: Findings for "always" and "most of the time" were merged; less than $1 \%$ of the sample chose "always" for each item. 
Most respondents (63\%) were extremely or very likely to prioritize giving such advice to parents. However, only $27 \%$ reported it was extremely or very likely that parents valued such advice and only $11 \%$ reported it was extremely or very likely that parents would follow such advice. (See Table 4 for more specific endorsement levels for each item.)

These findings varied by some professional characteristics (see Table 5). Men reported feeling less prepared and perceiving less preparedness amongst their colleagues than women. Whites, professions other than child welfare, mental health, and physicians, and those with less than 15 years of professional experience all reported feeling less prepared to advise parents than their counterparts. Compared with their counterparts, Non-Whites, and child welfare and mental health professionals, all reported perceiving more preparedness amongst their colleagues. Respondents that reported perceiving more value in advising parents on this topic were more likely to be Non-White, mental health professionals, and/or those with 15 or more years of experience.

\subsection{Motivation to change norms regarding $C P$}

Most respondents were very motivated to participate in activities designed to change norms regarding the use of $\mathrm{CP}$ (see Table 2). In particular, most were extremely or very motivated to: learn about ways to best intervene with parents when they spank children in their presence (73\%), talk to parents about using discipline techniques that do not involve spanking (71\%), learn more about research findings on the effects of spanking on children (70\%), challenge parents' viewpoints that support the use of spanking (67\%), challenge colleagues' viewpoints that support the use of spanking (67\%), discuss discipline techniques that do not involve CP with their colleagues (65\%), and work with their employer to change policies related to the use of spanking (53\%; see Table 6). Some respondents were more motivated than others to participate in these norms' changing activities: women, mental health professionals, those with 25-34 years of experience, and those who experienced CP often as children (see Table 5).

\subsection{Perceived professional barriers to advising parents about child discipline}

A majority reported that the main barriers to educating parents about the use of non-physical discipline were concerns about cultural sensitivity (59\%), lack of time (52\%) and lack of resources (50\%). Other perceived barriers included: lack of training about how to best advise parents (49\%), lack of confidence about how to best advise parents (42\%), lack of knowledge about how to best advise parents (42\%), lack of knowledge about what types of strategies would be more effective than spanking (41\%), discomfort with the topic (34\%), lack of reimbursement for the time spent advising parents (28\%), lack of incentive (26\%), and belief that this issue is not a priority in their profession (20\%). Other self-reported barriers included state laws that sanction CP, religious justification, and cultural norms that endorse CP as a disciplinary measure.

\section{Discussion}

A key step in reducing population rates of child maltreatment is to identify and reduce the most prevalent risk factors for maltreatment in society. As Klevens and Whitaker (2007) noted, "Social norms regarding physical discipline may be the most prevalent risk factor for child abuse in the United States" (p. 371). Understanding the current state of these injunctive social norms and related beliefs among professionals that work in the field of child maltreatment is a crucial step in changing broader population norms. These professionals will play a critical role in changing how parents, community leaders, and other professionals think about this issue.

\subsection{Attitudes and perceived norms}

There is a clear injunctive norm against the use of CP among this group of professionals. The vast majority of the sample endorsed items indicating disapproval of CP use. This alone is an important finding as it indicates a significant shift over the past two decades in professional injunctive norms regarding CP. Nearly half of our sample consists of mental health professionals and physicians. Similar studies among these professional groups in the past showed ambivalence and were not indicative of widespread disapproval of CP (i.e., American Academy of Pediatrics, 1998; McCormick, 1992; Schenck et al., 2000). This attitudinal shift among these groups is significant because these are the same groups of professionals that parents most rely on for advice about child discipline and they have strong potential for influencing parents' own attitudes toward CP (Taylor, Hamvas, Rice et al., 2011; Taylor et al., 2013). In addition, these professionals can influence norm shifting activities at the organizational level, such as No Hit Zones and position or policy statements, which can have broad societal impact.

Members of APSAC were very well-informed about the empirical evidence linking CP with many types of health risks for children. APSAC professionals understood that using CP with a child could lead to increased aggressive behavior, poorer mental health, and physical abuse victimization - all of which are findings strongly supported by the empirical literature (e.g., Afifi et al., 2012; Gershoff \& Grogan-Kaylor, 2016; Taylor, Manganello, Lee, \& Rice, 2010; Zolotor, Theodore, Chang, Berkoff, \& Runyan, 2008). A majority also were aware that $\mathrm{CP}$ has the potential to raise risk for poorer physical and neuro-cognitive health, although the research in these areas is less robust (e.g., Afifi et al., 2013; Bugental, Martorell, \& Barraza, 2003; Gershoff \& Grogan-Kaylor, 2016; Sheu, Polcari, Anderson, \& Teicher, 2010; Tomoda et al., 2009). Yet despite the strong level of knowledge these professionals exhibited on this topic, a majority still expressed strong motivation to learn even more about the research findings. Given that these professionals specialize in the field of child maltreatment, they are likely to be more knowledgeable and more motivated than others in their respective professions on this topic. 
This latter point might also explain the gap we found between the level of disapproval toward CP these respondents indicated and that which they perceived amongst their colleagues. Although 74-84\% endorsed disapproval of CP items, only 59-69\% perceived such disapproval amongst their colleagues, with gaps for individual items ranging from 11 to $20 \%$. Hence, they do perceive their colleagues disapprove of $\mathrm{CP}$, but not as strongly as they do. This might explain why some of our respondents reported feeling reticent to speak up about this topic with colleagues. A limitation of our research and challenge to interpreting this finding is that we don't know the universe of colleagues participants were referencing when responding to these questions. If the colleagues they were referencing are broader than those in APSAC, or in similar professional contexts, this gap between personal and perceived attitudes may indeed be accurate. However, if they were referencing their fellow APSAC colleagues, then this gap represents some pluralistic ignorance: where persons actually reject a norm privately (in this case, approval of $\mathrm{CP}$ ) but believe they are in the minority by doing so (Miller \& McFarland, 1987). Misperceived norms such as these have been shown to influence health-related behaviors (e.g., DeJong et al., 2006; Haines, 1996). So it might benefit professionals, and their clients, to know that their colleagues feel as strongly as they do about CP. This in turn might encourage more professionals to speak up more about this topic amongst their colleagues, which could again promote organizational or even broader community-level shifts in CP norms.

\subsection{Training needs and motivations}

Although most respondents were opposed to the use of CP and reported it to be harmful, this knowledge has not reached $100 \%$ saturation amongst these professionals. Hence more training is still needed on this topic to shift these attitudes and educate about the harms associated with CP. This is important on a number of levels. First, this minority group may still be advising parents that use of $\mathrm{CP}$ is acceptable and not harmful to children. Second, this minority group can have a significant influence on the field and delay social norms' change (Gardikiotis, 2011). For example, an influential minority group can prevent the passage of organizational or workplace policies, and even legislation that can help prevent the use of CP.

Further, although most respondents felt supported, confident, and well prepared in advising parents on appropriate, non-harmful child discipline techniques, they also noted some important barriers to doing so. Future professional training programs should pay special attention to concerns about cultural sensitivity and lack of knowledge about how best to advise parents. Regarding cultural sensitivity, it is important to start with the knowledge that support for $\mathrm{CP}$ is currently normative across racial and regional cultures in the U.S. (Child Trends Databank, 2015; Enten, 2014). In addition, the harmful effects of CP are not dampened by cultural normativeness (Gershoff, Lansford, Sexton, Davis-Kean, \& Sameroff, 2012). Nonetheless, both of these points should be addressed within the context of professional education that both employs and teaches cultural humility and sensitivity (Smith, HudnutBeumler, \& Scholer, 2016; Tervalon \& Murray-Garcia, 1998). Our respondents made suggestions for addressing this barrier such as providing "brief, web-based trainings or handouts on cultural issues with spanking and other forms of discipline" and emphasizing the "need for culturally diverse voices and leaders from all professions, including religious leaders, speaking out about...spanking."

Our respondents also cited a need for increased training regarding the empirical literature on the negative consequences of $\mathrm{CP}$, as well as on evidence-based practices for comfortably engaging with parents on this topic and reducing the use of CP with an emphasis on prevention. Ideally this sort of training could become more integrated in current professional training programs as well as through continuing education programs within professional organizations. For example, Child Advocacy Studies Training (CAST) curricula can be integrated within existing training programs (Knox, Pelletier, \& Vieth, 2013). An excellent option for professionals already in the field is a brief, web-based training program shown to reduce medical trainees' support for CP and increase their knowledge, comfort, and competence in advising parents about appropriate child discipline (Burkhart, Knox, \& Hunter, 2016; Scholer, Reich, Boshers, \& Bickman, 2005). This also is an excellent option in cases where time and resources are a significant barrier to training.

Different groups of professionals may also have different ranges of knowledge and needs, and training should be offered accordingly. Those with less experience may need additional assistance in seeing the value in advising and feeling prepared to advise parents on this topic. Also, variations in attitudes and beliefs about CP among professionals mirror those found in the general population (Child Trends Databank, 2015; Deater-Deckard, Lansford, Dodge, Pettit, \& Bates, 2003; Gagne et al., 2007; Taylor, Hamvas, Rice et al., 2011). Accordingly, those who have experienced CP in childhood, men, and non-White professionals may need more training regarding the negative outcomes of $\mathrm{CP}$ than their counterparts who have not experienced $\mathrm{CP}$, women, and White professionals, respectively.

Finally, respondents expressed doubt that parents would truly value and follow their advice about child discipline. However, both pediatricians and mental health professionals are the top professional groups that parents are most likely to seek and follow advice from, and whose opinions about CP are most strongly associated with parents' own (Fortson et al., 2013; Taylor, Hamvas, Rice et al., 2011; Taylor et al., 2013; Walsh, 2002). These findings should be shared with professionals to assure them that their advice is truly valued by parents.

\subsection{Study limitations}

Although we obtained a respectable response rate $(51 \%)$ for an online survey, it is unclear to what degree our sample is representative of the overall membership of APSAC. Furthermore, our survey presents a cross-sectional snapshot of the respondents' viewpoints, thus, we are unable to examine whether respondents' viewpoints related to CP have shifted over time. Related to this issue, it is possible that the results are influenced by self-presentational biases that are present with most survey research, and that respondents may have deduced a bias against $\mathrm{CP}$ from the nature of the survey questions. Although our measures had high reliability (see Table 1), some of them were created specifically for the purposes of this study, and therefore, the validity of the measures may be 
at issue. Importantly, we note that the APSAC organization is not representative of all child welfare professionals and furthermore is limited to a mostly U.S.-based membership. Future research should examine the attitudes, beliefs, perceived norms, motivations, and training needs related to $\mathrm{CP}$ of an international audience of child welfare professionals, as well as broaden to examine other organizations that serve health care, mental health, social worker, and public health professionals.

\section{Conclusions and implications}

Many professional organizations focused on child maltreatment prevention and child health promotion have been involved in efforts to change social norms regarding CP and reduce its use globally (Durrant \& Smith, 2011; United Nations Human Rights Office of the High Commissioner, 1989). The Center for Disease Control and Prevention's (CDC) recently released guide to preventing child maltreatment concurs that such strategies are needed, citing the need for both educational and legislative approaches to achieve this goal (Fortson, Klevens, Merrick, Gilbert, \& Alexander, 2016). Community leaders and professionals have the power to influence parents' approval and use of CP (Taylor, Hamvas, Rice et al., 2011; Taylor et al., 2013); hence, knowing that most APSAC professionals disapprove of CP use and believe it is harmful has major implications for shifting societal norms about CP. A multi-level strategy to shift these norms can aid in leveraging these findings.

First, professional organizations committed to bettering child health and welfare can issue statements recommending against the use of CP as many have already done (American Academy of Child and Adolescent Psychiatry, 2012; American Academy of Pediatrics, 2014; National Association of Pediatric Nurse Practitioners, 2011). Following the preliminary release of findings from this survey (Taylor \& Lee, 2015), APSAC adopted a position statement calling for "the elimination of all forms of corporal punishment and physical discipline of children in all environments including in schools and at home" (APSAC, 2016). Although this list is not comprehensive, it demonstrates that many of the leading organizations for child health and welfare professionals have already publicly denounced the use of CP. If more such organizations followed suit - such as the American Medical Association (AMA), American Psychological Association (APA), National Association of Social Workers (NASW), and International Society for the Prevention of Child Abuse and Neglect (ISPCAN)—this would be a major advancement in efforts to shift social norms supporting CP among U.S. adults.

Second, leaders within child health and welfare organizations can promote efforts to increase professional training opportunities on the harms of $\mathrm{CP}$ and how best to advise parents about healthy, developmentally appropriate options for child discipline. This is important not only for increasing knowledge on these topics but also for strengthening anticipatory guidance and counseling skills. Many relevant professional training and parent educational resources are already available. For example, brief interventions and materials such as Connected Kids (American Academy of Pediatrics, 2006), Play Nicely (Scholer et al., 2005), and SEEK (Dubowitz, Feigelman, Lane, \& Kim, 2009) have been developed for pediatricians. More extensive programs such as ACT (Knox, Burkhart, \& Cromly, 2013), Incredible Years (Beauchaine, Webster-Stratton, \& Reid, 2005), and Triple P Positive Parenting Program (Sanders, 2008) are available for counselors and mental health professionals. Finally, professionals can also engage in supporting and promoting community education efforts with broader population reach such as the dissemination of baby books found to reduce parents' use of CP (Reich, Penner, Duncan, \& Auger, 2012). Additionally, the development of No Hit Zone policies and educational campaigns in hospital settings can educate parents about not hitting as well as empower medical professionals and staff to intervene when they see parents using CP in hospital settings (Font et al., 2016; Frazier, Liu, \& Dauk, 2014).

\section{Author note}

We have many persons associated with the American Professional Society on the Abuse of Children (APSAC) to thank for our ability to conduct this survey. In particular, we thank APSAC Past President Frank Vandervort for his unwavering support in helping us launch and introducing the survey, APSAC prevention committee co-chairs Dave Corwin and Bart Klika as well as Deb Sendek for their guidance and support, and all members of the APSAC prevention committee who offered encouragement and support for the survey along the way. We especially thank APSAC staff members Laura Hughes and Susan Yingling for sending the survey linked introduction and reminders about the survey to the APSAC membership. We also would like to thank Carey Devine, Bridget Giglione, and Paloma Ellis for their assistance with the manuscript.

This work was supported in part by the Eunice Kennedy Shriver National Institute of Child Health \& Human Development [\#5K01HD058733].

\section{References}

American Professional Society on the Abuse of Children (2016). APSAC position statement on corporal punishment of children, 2016. from www.apsac.org/assets/ documents/Publications/apsac\%20position\%20statement $\% 20$ on $\% 20$ corporal\%20punishment $\% 20$ of $\% 20$ children $\% 20-\% 20$ final $\% 20$ approved $\% 207-26-16$.pdf.

Afifi, T. O., Mota, N. P., Dasiewicz, P., MacMillan, H. L., \& Sareen, J. (2012). Physical punishment and mental disorders: Results from a nationally representative US sample. Pediatrics, 130(2), 184-192. http://dx.doi.org/10.1542/peds.2011-2947.

Afifi, T. O., Mota, N., Macmillan, H. L., \& Sareen, J. (2013). Harsh physical punishment in childhood and adult physical health. Pediatrics, 132(2), e333-e340. http:// dx.doi.org/10.1542/peds.2012-4021.

Ajzen, I. (2005). Attitudes, personality, and behavior(2nd ed.). Milton-Keynes, England: Open University Press/McGraw-Hill.

Ajzen, I. (2006). Constructing a theory of planned behavior questionnaire. from http://www.people.umass.edu/aizen/pdf/tpb.measurement.pdf.

Altschul, I., Lee, S., \& Gershoff, E. T. (2016). Hugs, not hits: Maternal warmth, not spanking, predicts positive child behaviors in the first five years of life. Journal of Marriage and Family, 78(3), 695-714. http://dx.doi.org/10.1111/jomf.12306.

American Academy of Child, \& Adolescent Psychiatry (2012). Policy statement on corporal punishment retrieved june 6, 2016. from www.aacap.org/aacap/policy_ 
statements/2012/Policy_Statement_on_Corporal_Punishment.aspx.

American Academy of Pediatrics (1998). Periodic survey \#38: Attitudes and counseling on corporal punishment in the home. Periodic survey of fellows, division of child health research, executive summary Retrieved June 9, 2016, from www.aap.org/en-us/professional-resources/Research/Pages/PS38_Executive_Summary_ AttitudesandCounselingonCorporalPunishmentintheHome.aspx.

American Academy of Pediatrics (2006). In H. Spivak, R. D. Sege, E. Flanigan, \& V. Licenziato (Eds.), Connected kids: Safe, strong, secure. Elk Grove Village, IL: Boston Medical Center.

American Academy of Pediatrics (2014). AAP publications reaffirmed or retired, Vol. 134, Pediatricse1520 Elk Grove Village, IL.

Ashton, V. (2001). The relationship between attitudes toward corporal punishment and the perception and reporting of child maltreatment. Child Abuse and Neglect, 25(3), 389-399. http://dx.doi.org/10.1016/S0145-2134(00)00258-1.

Ateah, C., \& Durrant, J. (2005). Maternal use of physical punishment in response to child misbehavior: Implications for child abuse prevention. Child Abuse and Neglect, 29(2), 169-185. http://dx.doi.org/10.1016/j.chiabu.2004.10.010.

Beauchaine, T. P., Webster-Stratton, C., \& Reid, M. J. (2005). Mediators, moderators, and predictors of 1-year outcomes among children treated for early-onset conduct problems: A latent growth curve analysis. Journal of Consulting and Clinical Psychology, 73(3), 371-388. http://dx.doi.org/10.1037/0022-006X.73.3.371.

Berkowitz, A. D. (2003). Applications of social norms theory to other health and social justice issues. In H. W. Perkins (Ed.), The social norms approach to preventing school and college age substance abuse: A handbook for educators, counselors, clinicians (pp. 259-279). San Francisco, CA: Jossey-Bass.

Bohner, G., Reinhard, M.-A., Rutz, S., Sturm, S., Kerschbaum, B., \& Effler, D. (1998). Rape myths as neutralizing cognitions: Evidence for a causal impact of anti-victim attitudes on men's self-reported likelihood of raping. European Journal of Social Psychology, 28(2), 257-268.

Bugental, D. B., Martorell, G. A., \& Barraza, V. (2003). The hormonal costs of subtle forms of infant maltreatment. Hormones and Behavior, 43(1), 237-244. http://dx. doi.org/10.1016/S0018-506X(02)00008-9.

Burkhart, K., Knox, M. S., \& Hunter, K. (2016). Changing health care professionals' attitudes toward spanking. Clinical Pediatrics, 55(11), 1005-1011. http://dx.doi. org/10.1177/0009922816667313.

Child Trends Databank (2015). Attitudes towards spanking. from http://www.childtrends.org/?indicators=attitudes-toward-spanking.

Cialdini, R. B., Reno, R. R., \& Kallgren, C. A. (1990). A focus theory of normative conduct: Recycling the concept of norms to reduce littering in public places. Journal of Personality and Social Psychology, 58(6), 1015-1026. http://dx.doi.org/10.1037/0022-3514.58.6.1015.

DeJong, W., Schneider, S. K., Towvim, L. G., Murphy, M. J., Doerr, E. E., Simonsen, N. R., \& Scribner, R. A. (2006). A multisite randomized trial of social norms marketing campaigns to reduce college student drinking. Journal of Studies on Alcohol, 67, 868-879. http://dx.doi.org/10.1080/08897070902802059.

Deater-Deckard, K., Lansford, J. E., Dodge, K. A., Pettit, G. S., \& Bates, J. E. (2003). The development of attitudes about physical punishment: An 8-year longitudinal study. Journal of Family Psychology, 17(3), 351-360. http://dx.doi.org/10.1037/0893-3200.17.3.351.

Donnelly, M., \& Straus, M. A. (2005). Corporal punishment of children in theoretical perspective. New Haven: Yale University Press.

Dubowitz, H., Feigelman, S., Lane, W., \& Kim, J. (2009). Pediatric primary care to help prevent child maltreatment: The safe environment for every kid (SEEK) model. Pediatrics, 123(3), 858-864. http://dx.doi.org/10.1542/peds.2008-1376.

Durrant, J. E., \& Smith, A. B. (2011). Global pathways to abolishing physical punishment. New York: Routledge.

Durrant, J. E., Rose-Krasnor, L., \& Broberg, A. G. (2003). Physical punishment and maternal beliefs in Sweden and Canada. Journal of Comparative Family Studies, 34(4), $585-604$.

Enten, H. (2014). Americans' opinions on spanking vary by party, race, region and religion. FiveThirtyEight Retrieved from http://fivethirtyeight.com/datalab/ americans-opinions-on-spanking-vary-by-party-race-region-and-religion/.

Font, S. A., Gershoff, E. T., Taylor, C. A., Terreros, A., Nielsen-Parker, M., Spector, L., \& Olson-Dorff, D. (2016). Staff responses when parents hit children in a hospital setting. Journal of Developmental and Behavioral Pediatrics, 37(9), 730-736. http://dx.doi.org/10.1097/DBP.0000000000000343.

Fortson, B. L., Moseley, C., \& Burton, T. (2013). Use of audience segmentation and focus group research to better reach parents: Implications for child maltreatment prevention. Paper presented at the american professional society on the abuse of children 21st annual colloquium.

Fortson, B. L., Klevens, J., Merrick, M. T., Gilbert, L. K., \& Alexander, S. P. (2016). Preventing child abuse and neglect: A technical package for policy, norm, and programmatic activities. Atlanta, GA: National Center for Injury Prevention and Control, Centers for Disease Control and Prevention.

Frazier, E. R., Liu, G. C., \& Dauk, K. L. (2014). Creating a safe place for pediatric care: A no hit zone. Hospital Pediatrics, 4(4), 247-250. http://dx.doi.org/10.1542/ hpeds.2013-0106.

Gagne, M.-H., Tourigny, M., Joly, J., \& Pouliot-Lapointe, J. (2007). Predictors of adult attitudes toward corporal punishment of children. Journal of Interpersonal Violence, 22(10), 1285-1304. http://dx.doi.org/10.1177/0886260507304550.

Gardikiotis, A. (2011). Minority influence. Social and Personality Psychology Compass, 5(9), 679-693. http://dx.doi.org/10.1111/j.1751-9004.2011.00377.x.

Gershoff, E. T., \& Grogan-Kaylor, A. (2016). Spanking and child outcomes: Old controversies and new meta-analyses. Journal of Family Psychology, 30(4), 453-469. http://dx.doi.org/10.1037/fam0000191.

Gershoff, E. T., Lansford, J. E., Sexton, H. R., Davis-Kean, P., \& Sameroff, A. J. (2012). Longitudinal links between spanking and children's externalizing behaviors in a national sample of White, Black, Hispanic, and Asian American families. Child Development1, 1-6. http://dx.doi.org/10.1111/j.1467-8624.2011.01732.x.

Gershoff, E. T., Font, S. A., Taylor, C. A., Foster, R. H., Garza, A. B., Olson-Dorff, D., \& Spector, L. (2016). Medical center staff attitudes about spanking. Child Abuse and Neglect, 61, 55-62. http://dx.doi.org/10.1016/j.chiabu.2016.10.003.

Haines, M. P. (1996). A social norms approach to preventing binge drinking at colleges and universities. U.S. Department of Education The Higher Education Center for Alcohol and Other Drug Prevention32.

Holden, G. W., Coleman, S. M., \& Schmidt, K. L. (1995). Why 3-year-old children get spanked: Parent and child determinants as reported by college-educated mothers. Merrill-Palmer Quarterly, 41(4), 431-452.

Holden, G. W., Miller, P. C., \& Harris, S. D. (1999). The instrumental side of corporal punishment: Parents' reported practices and outcome expectancies. Journal of Marriage and the Family, 61(4), 908-919. http://dx.doi.org/10.2307/354012.

Holden, G. W. (2001). Attitude toward spanking (ATS). In J. Touliatos, B. F. Perlmutter, \& G. W. Holden (Vol. Eds.), Handbook of family measurement techniques. Vol. 2 , (pp. 209-). Thousand Oaks, CA: Sage.

Hornor, G., Bretl, D., Chapman, E., Chiocca, E., Donnell, C., Doughty, K., \& Quinones, S. G. (2015). Corporal punishment: Evaluation of an intervention by PNPs. Journal of Pediatric Health Care: Official Publication of National Association of Pediatric Nurse Associates and Practitioners, 29(6), 526-535. http://dx.doi.org/10.1016/ j.pedhc.2015.04.016.

Jent, J. F., Eaton, C. K., Knickerbocker, L., Lambert, W. F., Merrick, M. T., \& Dandes, S. K. (2011). Multidisciplinary child protection decision making about physical abuse: Determining substantiation thresholds and biases. Children and Youth Services Review, 33(9), 1673-1682. http://dx.doi.org/10.1016/j.childyouth.2011.04. 029.

Klevens, J., \& Whitaker, D. J. (2007). Primary prevention of child physical abuse and neglect: Gaps and promising directions. Child Maltreatment, 12(4), 364-377. http://dx.doi.org/10.1177/1077559507305995.

Knox, M. S., \& Brouwer, J. (2008). Early childhood professionals' recommendations for spanking young children. Journal of Child and Adolescent Trauma, 1(4), 341-348. http://dx.doi.org/10.1080/19361520802505719.

Knox, M. S., Burkhart, K., \& Cromly, A. (2013). Supporting positive parenting in community health centers: The ACT raising safe kids program. Journal of Community Psychology, 41(4), 395-407. http://dx.doi.org/10.1002/jcop.21543.

Knox, M. S., Pelletier, H., \& Vieth, V. (2013). Effects of medical student training in child advocacy and child abuse prevention and intervention. Psychological Trauma: Theory, Research, Practice, and Policy, 6(2), http://dx.doi.org/10.1037/a0031743.

Mackenzie, M. J., Nicklas, E., Brooks-Gunn, J., \& Waldfogel, J. (2015). Spanking and children's externalizing behavior across the first decade of life: Evidence for transactional processes. Journal of Youth and Adolescence, 44(3), 658-669. http://dx.doi.org/10.1007/s10964-014-0114-y.

McCormick, K. F. (1992). Attitudes of primary care physicians toward corporal punishment. JAMA, 267(23), 3161-3165. http://dx.doi.org/10.1001/jama.1992. 03480230053027.

Miller, D. T., \& McFarland, C. (1987). Pluralistic ignorance: When similarity is interpreted as dissimilarity. Journal of Personality and Social Psychology, 53(2), 298-305. 
http://dx.doi.org/10.1037/0022-3514.53.2.298.

National Association of Pediatric Nurse Practitioners (2011). NAPNAP position statement on corporal punishment. Journal of Pediatric Health Care, 25(6), e31-e32. http://dx.doi.org/10.1016/j.pedhc.2011.07.003.

Olson, L. M., Inkelas, M., Halfon, N., Schuster, M. A., O'Connor, K. G., \& Mistry, R. (2004). Overview of the content of health supervision for young children: Reports from parents and pediatricians [Cross-sectional]. Pediatrics, 113(6 Suppl), 1907-1916.

Reich, S. M., Penner, E. K., Duncan, G. J., \& Auger, A. (2012). Using baby books to change new mothers' attitudes about corporal punishment. Child Abuse \& Neglect, 36(2), 108-117. http://dx.doi.org/10.1016/j.chiabu.2011.09.017.

Reno, R. R., Cialdini, R. B., \& Kallgren, C. A. (1993). The transsituational influence of social norms. Journal of Personality and Social Psychology, 64(1), 104-112. http:// dx.doi.org/10.1037/0022-3514.64.1.104.

Sanders, M. R. (2008). Triple P-Positive Parenting Program as a public health approach to strengthening parenting. Journal of Family Psychology, 22(4), 506-517. http://dx.doi.org/10.1037/0893-3200.22.3.506.

Schenck, E. R., Lyman, R. D., \& Bodin, S. D. (2000). Ethical beliefs, attitudes, and professional practices of psychologists regarding parental use of corporal punishment: A survey. Children's Services: Social Policy, Research, and Practice, 3(1), 23-38. http://dx.doi.org/10.1207/S15326918CS0301_2.

Scholer, S. J., Reich, S. M., Boshers, R. B., \& Bickman, L. (2005). A multimedia violence prevention program increases pediatric residents' and childcare providers' knowledge about responding to childhood aggression. Clinical Pediatrics, 44(5), 413-417. http://dx.doi.org/10.1177/000992280504400505.

Sege, R. D., Hatmaker-Flanigan, E., De Vos, E., Levin-Goodman, R., \& Spivak, H. (2006). Anticipatory guidance and violence prevention: Results from family and pediatrician focus groups. Pediatrics, 117(2), 455-463. http://dx.doi.org/10.1542/peds.2005-0377.

Sheu, Y.-S., Polcari, A., Anderson, C. M., \& Teicher, M. H. (2010). Harsh corporal punishment is associated with increased T2 relaxation time in dopamine-rich regions. Neuroimage, 53(2), 412-419. http://dx.doi.org/10.1016/j.neuroimage.2010.06.043.

Smith, A. E., Hudnut-Beumler, J., \& Scholer, S. J. (2016). Can discipline education be culturally sensitive? Maternal and Child Health Journal1, 1-10. http://dx.doi.org/ 10.1007/s10995-016-2107-9.

Taylor, C. A., \& Lee, S. J. (2015). APSAC members' opinions, training needs, and practices regarding advising parents about child discipline and use of corporal punishment. Paper presented at the american professional society on the abuse of children.

Taylor, C. A., Guterman, N. B., Lee, S. J., \& Rathouz, P. J. (2009). Intimate partner violence, maternal stress, nativity, and risk for maternal maltreatment of young children. American Journal of Public Health, 99(1), 175-183. http://dx.doi.org/10.2105/AJPH.2007.126722.

Taylor, C. A., Moeller, W., Hamvas, L., \& Rice, J. C. (2013). Parents' professional sources of advice regarding child discipline and their use of corporal punishment. Clinical Pediatrics, 52(2), 147-155. http://dx.doi.org/10.1177/0009922812465944.

Taylor, C. A., Hamvas, L., \& Paris, R. (2011). Perceived instrumentality and normativeness of corporal punishment use among Black mothers. Family Relations, 60(1), 60-72. http://dx.doi.org/10.1111/j.1741-3729.2010.00633.x.

Taylor, C. A., Hamvas, L., Rice, J. C., Newman, D., \& DeJong, W. (2011). Perceived social norms, expectations, and attitudes toward corporal punishment among an urban community sample of parents. Journal of Urban Health, 88(2), 254-269. http://dx.doi.org/10.1007/s11524-011-9548-7.

Taylor, C. A., Lee, S. J., Guterman, N. B., \& Rice, J. C. (2010). Use of spanking for 3-year-old children and associated intimate partner aggression or violence. Pediatrics, 126(3), 415-424. http://dx.doi.org/10.1542/peds.2010-0314.

Taylor, C. A., Manganello, J. A., Lee, S. J., \& Rice, J. C. (2010). Mothers' spanking of 3-year-old children and subsequent risk of children's aggressive behavior. Pediatrics, 125(5), e1057-e1065. http://dx.doi.org/10.1542/peds.2009-2678.

Tervalon, M., \& Murray-Garcia, J. (1998). Cultural humility versus cultural competence: A critical distinction in defining physician training outcomes in multicultural education. Journal of Health Care for the Poor and Underserved, 9(2), 117-125. http://dx.doi.org/10.1353/hpu.2010.0233.

Tirosh, E., Shechter, S. O., Cohen, A., \& Jaffe, M. (2003). Attitudes towards corporal punishment and reporting of abuse. Child Abuse and Neglect, 27(8), 929-937. http://dx.doi.org/10.1016/s0145-2134(03)00140-6.

Tomoda, A., Suzuki, H., Rabi, K., Sheu, Y.-S., Polcari, A., \& Teicher, M. H. (2009). Reduced prefrontal cortical gray matter volume in young adults exposed to harsh corporal punishment. Neuroimage, 47(Suppl. 2), T66-71. http://dx.doi.org/10.1016/j.neuroimage.2009.03.005.

United Nations Human Rights Office of the High Commissioner (1989). Convention on the Rights of the Child. from http://www.ohchr.org/en/professionalinterest/ pages/crc.aspx.

Vittrup, B., Holden, G. W., \& Buck, J. (2006). Attitudes predict the use of physical punishment: A prospective study of the emergence of disciplinary practices. Pediatrics, 117(6), 2055-2064. http://dx.doi.org/10.1542/peds.2005-2204.

Walsh, W. (2002). Spankers and nonspankers: Where they get information on spanking. Family Relations, 51(1), 81-88. http://dx.doi.org/10.1111/j.1741-3729.2002. 00081.x.

Wolraich, M. L., Aceves, J., Feldman, H. M., Hagan, J. F., Howard, B. J., Richtsmeier, A. J., \& Tolmas, H. C. (1998). Guidance for effective discipline. Pediatrics, 101(4), $723-728$.

Zolotor, A. J., Theodore, A. D., Chang, J. J., Berkoff, M. C., \& Runyan, D. K. (2008). Speak softly - and forget the stick: Corporal punishment and child physical abuse. American Journal of Preventive Medicine, 35(4), 364-369. http://dx.doi.org/10.1016/j.amepre.2008.06.031.

Zolotor, A. J., Robinson, T. W., Runyan, D. K., Barr, R. G., \& Murphy, R. A. (2011). The emergence of spanking among a representative sample of children under 2 years of age in North Carolina. Frontiers in Psychiatry, 2, 1-8. http://dx.doi.org/10.3389/fpsyt.2011.00036. 